\title{
Challenges in Evaluation and Management of Children with Myocardial Bridging
}

\author{
Nurdan Erol
}

Pediatric Clinics, Zeynep Kamil Gynecology and Pediatrics Training and Research Hospital, Health Sciences University, Uskudar/Istanbul, Turkey

\section{Keywords}

Angiography $\cdot$ Children $\cdot$ Congenital heart disease .

Coronary arteries

\begin{abstract}
Myocardial bridging (MB) is a congenital anomaly where a coronary artery branch or group of branches extends inside a tunnel consisting of myocardium. Although it is mostly considered "benign," it is reported that MB may lead to significant cardiac problems and sudden cardiac deaths. While it is a congenital anomaly, its symptoms usually arise at further ages rather than childhood. The literature on MB in children is in the form of case reports or small case series. This is why pediatric cases are assessed in the light of information obtained from adults. This review compiled the literature on $M B$ in adults and children and compared it, as well as discussing questions arising regarding the clinic, diagnosis, and treatment of MB.

๑) 2021 S. Karger AG, Basel
\end{abstract}

\section{Introduction}

Myocardial bridging (MB) is a congenital anomaly of the coronary arteries where one or more parts of a coronary artery or arteries progresses inside a tunnel made out of myocardium $[1,2]$. MB was anatomically defined for the first time by Reynman [3]. It was shown angiographically for the first time by Portman and Iwig [4]. This anomaly is found on all coronary arteries, especially on the medial and distal parts of the left anterior descending artery (LAD) [1, 2,5-12]. Although it is seen as a normal anatomical variant as it is mostly benign and asymptomatic, it was reported that it may lead to cardiac outcomes such as angina, myocardial ischemia, acute coronary syndrome, left ventricular dysfunction/stunning, arrythmia, and cardiac sudden death $[1,6,13]$. The criteria to be used in diagnosis and monitoring are not yet clear regarding this anomaly that has been recognized for a long time and whose physiology and pathophysiology are aimed to be explained with new diagnosis and identification opportunities [1].

Although it is accepted as a congenital variant of the coronaries, studies on MB in childhood and adolescents have not gone beyond case reports and small case series [14-20]. Symptoms that are considered to belong to MB usually emerge in adulthood and at further ages [12]. Most studies on the topic also focus on these agegroups. While $\mathrm{MB}$ is assessed in children and adolescents, these studies are mostly taken as a basis. There are no universally accepted criteria regarding making a diagnosis of $\mathrm{MB}$ in children and monitoring and treatment of these cases when a diagnosis is made. This re- karger@karger.com

www.karger.com/crd

Karger $\stackrel{2}{*}$
(C) 2021 S. Karger AG, Basel

(n)
Nurdan Erol

Pediatric Clinics, Zeynep Kamil Gynecology and Pediatrics Training and Research Hospital, Health Sciences University, Dr. Burhanettin Ustunel Sokagi No. 10 Uskudar/Istanbul 34668 (Turkey)

nurdaneroltr61@gmail.com 
view compiled and compared the literature on $\mathrm{MB}$ in adults and children and discussed questions arising on this topic.

\section{Prevalence}

It is accepted that $\mathrm{MB}$ occurs in the fetal period during development of the coronaries [7-9]. Demonstration of $\mathrm{MB}$ in cases dying due to a noncardiac reason in the fetal and newborn periods proves this $[20,21]$. The prevalence of $\mathrm{MB}$ shows differences based on societies and diagnostic possibilities $[8,22]$. The mean prevalence of $\mathrm{MB}$ is reported as 33\% (15-85\%) in autopsy series, 5\% (0.5-16\%) coronary angiographies, and $21 \%(3.5-38.5 \%)$ in coronary CT angiocardiographies [1]. It may be stated that the prevalence of $\mathrm{MB}$ is around $25 \%$ on average $[1,23]$. Its prevalence does not vary based on age and sex [24]. In a study on the hearts of 30 -week-old fetuses lost due to various causes, $\mathrm{MB}$ was determined to have a rate of $46.2 \%$ [25]. This rate was compatible with the MB rates reported in autopsies. These findings prove that the condition is congenital. It may be considered that $\mathrm{MB}$ is around these rates also in children. It was reported to be more prevalent in some patient groups (such as hypertrophic cardiomyopathy, transplant heart cases) $[1,2,12]$. It was stated that MB may be a result of an evolutionary residue [9], or it may occur due to a defect in the resorption of the muscular structure surrounding the epicardial arteries during morphogenesis [26].

\section{Types}

MB does not have a single type, but it may be in different lengths and depths or in different numbers on different coronaries and coronary branches. It was reported that a typical MB has a depth of $1-10 \mathrm{~mm}$ and a length of 10-30 mm [1, 27].

For the first time, Ferreira et al. [24] divided MB cases into 2 groups as superficial and deep. They stated that most cases (75\%) consist of superficial cases, and obstruction in this group is rare. Kim et al. [11] divided superficial cases as full and partial encasement. They stated that those in the full encasement group are associated with obstruction.

In CT angiocardiography, Konen et al. [28] divided $\mathrm{MB}$ findings into 3 groups as the superficial $(<1 \mathrm{~mm})$, deep $(>1 \mathrm{~mm})$, and right ventricular types. Noble et al. [29] categorized the systolic coronary narrowing into 3 classes: class 1 (systolic coronary narrowing $<50 \%$ ), class 2 (systolic coronary narrowing $50-75 \%$ ), and class 3 (systolic coronary $>75 \%$ ). Schwarz et al. [30] categorized MB as type $\mathrm{A}, \mathrm{B}$, and $\mathrm{C}$ based on clinical and angiography findings. Nevertheless, in terms of easy classification of the pathology, it will be appropriate to divide it into 2 groups as superficial and deep.

Ferreira et al. [24] reported that $\mathrm{MB}$ was found in 1 coronary artery in $70 \%$ of cases, 2 coronary arteries in $20 \%$, and 3 coronary arteries in $10 \%$. It was specified that while MB may be a single coronary anomaly, it may also be found to be accompanied by other coronary anomalies and other congenital cardiac pathologies $[17,20]$. $M B$ is frequently seen in the medial and distal part of the LAD $[1,2,5-13,31,32]$.

\section{Pathology and Pathophysiology}

It is thought that MB-related events are associated with the dynamic obstruction that is formed by the contraction of the myocardial tissue causing bridging $[6,13]$ or early atherosclerosis forming in the proximal of $\mathrm{MB}[6$, $13]$. When cadavers with $M B$ were examined, it was determined that the endothelium in the proximal part of the coronary artery and in the bridging part was different $[1$, $2,7]$. The endothelial structure under bridging consists of contractile-type smooth muscle cells which are thinner in comparison to the proximal, and these produce spiraltype collagen. The endothelial cells in the proximal part are synthetic type cells, and they start atherosclerosis by experiencing proliferation and increasing the production of collagen and elastic fibrils [2].

It is considered that the element causing the change in the endothelium and the atherosclerosis in the proximal is the low-wall shear stress in the proximal part [33]. The bridging part is protected from atherosclerosis due to high-wall shear stress. Studies have either not observed or rarely observed atherosclerosis in the bridging part and the distal of the coronary artery $[7,34,35]$. Cheng et al. [36] reported that the expression of proatherogenic inflammatory mediators and matrix metalloproteins is higher in regions with low-wall shear stress, and accordingly, the atherosclerosis load is higher in these regions [34]. It was additionally shown that the endothelial nitric oxide synthase enzyme, endothelin-1, and angiotensinconverting enzyme are found less in the bridging part and more in the proximal part $[2,33]$.

In the review by Tarantini et al. [37], it is argued that the symptoms associated with $\mathrm{MB}$ are due to pathophysio 
pathological factors rather than anatomical factors. Various factors such as the patient's age, LV hypertrophy, local or general atherosclerosis of the coronaries may unmask or exacerbate the symptoms associated with MB. These factors impair coronary perfusion by decreasing the duration of diastole and the amount of blood that is filled during this period and prolonging the duration of arterial spasm relaxation. As a result, subendocardial and transmural ischemia develops. Septal ischemia develops due to the "branch steal" caused by the venturi effect in the septal branches in the MB. In addition, retrograde flow suppresses the anterograde flow and increases wall shear stress in the proximal part of the coronary, leading to atherosclerosis formation. All of these factors combined contribute to the emergence of the clinical findings related to $\mathrm{MB}$ [37].

\section{Diagnosis}

Diagnosis is made classically with systolic obstruction, "milking effect" or "step up-step down" appearance on the coronary in conventional angiocardiography. In angiocardiography, MB may be observed in relation to the degree of systolic obstruction [7, 29]. It was observed that the $\mathrm{MB}$ diagnosis in angiocardiographies increased by $40 \%$ by nitroglycerin inhalation [38]. CT angiocardiography (initially electron-beam CT and lately multi-slice CT) has an important place in diagnosis. In multi-slice CT (especially 64-124) angiocardiography [1], MB was determined at a rate close to those in cadavers [28]. The usability of this technique in children was demonstrated [39]. Findings obtained by conventional angiocardiography and MSCT show the anatomical characteristics of MB.

Although $\mathrm{MB}$ is a highly frequently encountered anomaly in cadaver studies, the events encountered at the clinic are not that frequent. Distinguishing $\mathrm{MB}$, which has a clinical significance, is vital for treatment. To achieve this, Ge et al. [40] conducted a study on functional assessment with intravenous ultrasonography and intravenous Doppler. With intravenous ultrasonography, they demonstrated a "half-moon phenomenon" appearance thought to be associated with systolic pressure inside bridging and atherosclerosis in the proximal region in $88 \%$ [40]. With IV Doppler, they showed flow patterns in the proximal and inside bridging, increased flow velocity at early diastole (finger-tip phenomenon), reduced or lost systolic antegrade flow, reduced diastolic/systolic velocity ratio, retrograde flow in the proximal segment, and that these were provoked more with nitroglycerin [41]. Escaned et al. [42] emphasized in their study that in addition to classical fractional flow reserve (FFR), dobutamine challenge and diastolic FFR should also be measured [43]. However, these are invasive tests.

Zeina et al. [44] reported that there was a relationship between MB length and depth and atherosclerosis in the proximal. In their study comparing MSCT angiocardiography and conventional angiocardiography, Kim et al. [11] stated that dynamic compression is associated with MB length. It was shown full encasement of LAD (97.5\%) in MSCT angiocardiography is related to dynamic obstruction in conventional angiocardiography [11]. It may be stated that it would be useful to functionally assess CT angiocardiography. CT will also be helpful in demonstration and preoperative assessment of $\mathrm{MB}$ cases close to the right ventricular cavity.

Yamada et al. [45] stated that MB symptoms are related to atherosclerotic load found in the proximal of bridging. Kobayashi et al. [46] observed that in MB cases shown to be significant by diastolic flow reserve examination, the change in the septal longitudinal strain in stress echocardiography was lower, and this could be used for the purpose of noninvasive assessment.

MSCT is a diagnostic tool that could be considered at the first stage in cases in children requiring MB differential diagnosis and showing or not showing signs of myocardial ischemia. It would be appropriate to carry out other invasive interventions in cases with severe obstruction and possibility of decision for surgical treatment.

\section{Clinic}

Whether $\mathrm{MB}$ is an anatomical variant or pathological condition has been discussed [1, 2, 4-13]. While some authors defended the idea that it is not significant [47], others argued that it has significant outcomes $[6,48]$. It has been reported in different studies in the literature that this pathology causes angina-like chest pain, coronary spasm, myocardial ischemia, acute coronary syndrome, coronary artery spasm, left ventricular dysfunction/stunning [49], arrythmias (supraventricular and ventricular) [50], exercise-induced atrioventricular block, transient ventricular dysfunction, early death after cardiac transplantation, and even sudden cardiac death $[1,2,6]$.

It may usually take up to the third decade of life for this pathology that is known to develop in the fetal period and found highly prevalently in autopsies to present symptoms. Pereira et al. [51] attributed the fact that MB-related 
problems present late in the late period to increased pressure in the myocardial wall, increased left ventricular enddiastolic pressure in relation to the development of the heart, myocardial hypertrophy secondary to arterial hypertension, and developing atherosclerotic coronary events. It may be proposed that MB-related events will show symptoms earlier when cardiac risk factors such as hypertension, diabetes and obesity start in the childhood period or in cardiac remodeling occurring in intense sports. MB-related symptoms in childhood and adolescence are also not clear. On the other hand, it was reported that there are also cases at childhood and adolescence ages that present with severe problems and sudden cardiac death $[52,53]$. In addition to athletes who experience sudden cardiac death without any previous complaints [54], there are also cases that are taken into operation [55].

Although $\mathrm{MB}$ is a frequently encountered anomaly, another reason for it to present fewer clinical signs is that there are highly varied types of bridging cases. It is more likely to associate cases with deep MB with the clinic and cardiac symptoms, and the rate of these is lower.

It was reported that $\mathrm{MB}$ is more frequently encountered in children and adults with hypertrophic cardiomyopathy $[1,2,6]$. Yetman et al. [15] determined MB in $28 \%$ of 36 pediatric cases with hypertrophic cardiomyopathy, and they thought that $\mathrm{MB}$ is associated with myocardial ischemia in this patient group. There are also studies arguing the opposite case. Mouhiddin et al. [16] reported that bridging and compression in the septal branches are higher in these cases, this is associated with LV hypertrophy, and this will lead to myocardial perfusion anomalies. However, they stated that MB will not lead to myocardial ischemia in this group [16]. While Yetman et al. [15] argued that QTc dispersion is higher in $\mathrm{MB}$ cases and paves the way for arrythmia, Mouhiddin et al. [16] claimed the opposite.

In their study on adults with hypertrophic cardiomyopathy, van der Velde et al. [56] determined MB to be 2 times higher in comparison to the control group, and they reported that this does not lead to a reduction in lifespan due to chest pain and cardiac events. As MB is seen in close to half of hypertrophy cases, whether this accompanies hypertrophy or is a part of a single pathology was debated [57]. There are also pediatric cases in whom hypertrophic cardiomyopathy is not observed. In an 11year-old female case arriving with chest pain and syncope whose tests were normal, in whom ST changes were observed during syncope, who was sent to diagnosis with findings of ischemia in scintigraphy and did not respond to medical treatment, it was observed that there were no complaints in the 2-year period after surgery [18].
Comorbidity of $\mathrm{MB}$ with other congenital pathologies has been reported. Gerlis et al. [20] associated the worsening of the clinical outcome in a newborn case who was operated due to coronary aortic orifice obstruction with $\mathrm{MB}$ that was found with this pathology. In a 13-year-old female case who experienced ventricular fibrillation while exercising, Lezzi et al. [17] detected MB in LAD in addition to anomaly in the right coronary artery. In functional examination, it was determined that this was pathological, $\mathrm{MB}$ was treated by unroofing while fixing the coronary anomaly, and no problem was observed in the 6-month followup [17]. In the study by Kiess et al. [19], it was stated that $\mathrm{MB}$ accompanying the other underlying cardiological cause would increase the severity of the event.

Sudden cardiac death is a problematic situation that is encountered in regular individuals and athletes. MB was found in LAD in 13 of 22 sudden cardiac death cases, while the sudden cardiac death took place during effort in 6 of these deaths. Occasionally, participation examination is carried out in athletes before sports. It is possible to encounter MB in some athletes. However, it is difficult to make a diagnosis without symptoms. Despite being considered benign, even its superficial types have been shown to lead to thrombus formation, and in young athletes, myocardial infarction [53]. Non-atherosclerotic coronary anomaly was determined in 16 of 48 cadavers with a history of sudden cardiac death at the ages of 2-35, while $\mathrm{MB}$ was determined in 6 of these (approximately $10 \%$ ) [53]. MB dimensions were measured as $10-25 \mathrm{~mm}$ in length and 4-8 $\mathrm{mm}$ in depth. Syncope, arrythmia, or monitored chest pain was not specified in the histories of these cases. Findings belonging to infarction and previously experienced cardiac events were determined in these cases [53]. This suggests that MB is not innocent. It was argued that intramural muscular disarray and fibrotic changes may prevent diastolic relaxation during effort [53]. It is known that there are especially athletes without complaints who had sudden cardiac death during exercise. In a young case who took part in sports professionally and had normal previous examinations, it was shown that there was MB in 3 arteries after the case died by ventricular fibrillation [26].

A meta-analysis in the literature reported that $\mathrm{MB}$ is associated with coronary events and vasospasm [58]. Ge and Ishikawa reported that atherosclerosis plaque increases the risk of myocardial infarction by the degree it gets closer to the proximal of the coronary $[40,41,59]$. In their study which compared $\mathrm{MB}$ cases and cases without $\mathrm{Mb}$ by the acetylcholine provocation test, Saito et al. [60] showed that the severity of bridging and coronary spasm were as- 
sociated in those who had MB. MB's localization, depth, length, and the contractility of the heart muscle affect the severity of the obstruction in the coronary arteries [2].

It was reported that $\mathrm{MB}$ is higher in transplantation cases. This was attributed to an increase in the stiffness of the myocardium [61].

Migliero et al. [62] determined that the MB rates in cases with apical ballooning (40\%) were higher in comparison to the control group (8\%). Kato et al. [63] showed that in hospitalized Takasubo syndrome cases, death was more prevalent in those with $\mathrm{MB}(21 \%)$ in comparison to those without (6\%). On the other hand, there are no studies on this topic related to the childhood period.

A meta-analysis examining 21 studies reported that $\mathrm{MB}$ had a negative effect on major cardiac events $(-\mathrm{OR}=$ $1.52[1.01-2.30])$ and associated with myocardial ischemia $(\mathrm{OR}=3.00[1.02-8.82])$, while it was not related to myocardial infarction, cardiac death, tests that are used, and the positive exercise test [58].

\section{Treatment}

Schwarz et al. [64] demonstrated a decrease in the systolic flow caused by MB during tachypacing, a change in the systolic/diastolic flow rates, and that ST depressions were carried to normal values by using short-acting betablockers. Betablockers are useful in reducing MB-originated symptoms by reducing the contraction of the myocardium in the bridging region and tachycardia.

This is why betablockers or calcium channel blockers are recommended today as the first treatment option in symptomatic $\mathrm{MB}$ cases [1, 2, 4-13]. As demonstrated by studies, nitroglycerin needs to be avoided [6]. Nevertheless, there are no controlled longitudinal studies on these drugs showing that they treat $\mathrm{MB}$, protect individuals from cardiac death, delay or prevent surgical treatment.

It was reported that severe complications such as stent fracture and coronary perforation developed in some $\mathrm{MB}$ cases on whom percutaneous coronary interventions such as stent implantation were applied $[1,2,65]$. Haager et al. [66] stated that a stent eliminated external compression in the artery with bridging, increased the luminal width, and reduced symptoms, and these cases showed a good prognosis in a 2-year follow-up. In their cadaver study, Pourhusaini et al. [67] claimed that changes in the proximal and distal parts and that the bridging part is thinner may be the reason for the higher rate of complications in invasive interventions. Nevertheless, stent application may be only suitable for a limited number of cases and at further ages due to its complications. Invasive interventions are not suitable for the period of childhood.

Surgical treatment is recommended in MB cases not responding to medical treatment. Unroofing myectomy is the first recommended surgical treatment method due to its low rate of complications, easy applicability, and good outcomes $[68,69]$. Coronary bypass operation is one of the other options, while it has been safely used in adult MB patients [70-72].

It has been reported that surgical treatment may also be used safely in pediatric patients $[14,73]$. In a group of surgery patients consisting of 14 individuals under the age of 21 , it was reported that surgical treatment provided good outcomes with a low risk. It was shown that unroofing myotomy anatomically fixed coronary flow and eliminated MB symptoms [14]. In Maeda et al.'s [14] study, no significant difference was found between the adult and pediatric groups in terms of MB-related halo width, compression, length, and dFFR. The maximum plaque load was found to be lower in children than adults (adult 33.9 $14.3 \%$ vs. pediatric $18.54 .9 \%$ ). This shows that atherosclerosis increases by age. In this group, the atherosclerosis plaque was found at approximately $2 \mathrm{~cm}$ above the $\mathrm{MB}$ segment in all cases [14].

Kikuchi et al. [74] determined MB and plaque by 15.6 $\mathrm{mm}$ above in a 28 -year-old young male case. In this case, they reported that the clinical picture progressed well by only a drug-coated balloon and 3 months of dual antiplatelet therapy [74]. Although adults are sent for surgery more frequently, medical treatment is preferred more in young cases. Early surgical treatments are also recommended due to the long nature of medical treatment, problems created by the treatment compliance process, and the progressive nature of the condition [75].

\section{Prognosis}

The study by Kim et al. [76] on adults showed that MB may cause chest pain, myocardial infarction, or lifethreatening arrythmia in cases with a mean follow-up of 37 weeks who had MB (especially long and those showing vasospasm) without atherosclerotic coronary diseases. They reported that this should be treated by medical and antiplatelet treatment [76].

Dimitriu-Leen et al. [77] retrospectively determined MB in 22\% of the cases in the CT examination of 947 cases with a mean age of approximately 54 . It was proposed that in a 6-year follow-up, groups in whom $\mathrm{MB}$ was determined ( $40 \%$ deep) and not determined showed sim- 
ilar characteristics in terms of cardiac events [77]. Although the authors reported that $\mathrm{MB}$ does not increase the risk of myocardial events [77], there was no functional assessment in the study. In the meta-analysis, it was stated that MB may have significant cardiac outcomes, but there is a need for more studies on this topic [58].

\section{Conclusion}

To this day, various studies have been conducted on $\mathrm{MB}$, yet many questions regarding this condition still remain. Although a majority of $\mathrm{MB}$ cases are considered to be benign, it is not known for certain whether MB plays a role in the etiologies of other cardiovascular conditions or increases the risk of developing other diseases in the future. In order to prevent such risk factors, MB should be considered during the differential diagnoses of cases with symptoms like frequent nonspecific chest pain, effort dyspnea, and syncope without a known cause and treatment should be administered accordingly. On that matter, currently, there are no criteria on the treatment of children with $\mathrm{MB}$ and due to the lack of data regarding $\mathrm{MB}$ in children and adolescents, the findings of studies conducted on adults are used as a basis for treatment. The insufficient number of studies and the uncertainties regarding $\mathrm{MB}$ in children makes it necessary to carry out studies at multiple centers with a higher number of cases, prospective designs, and long-term follow-ups. With such studies, diagnostic and treatment protocols and cri- teria regarding pediatric patients with $\mathrm{MB}$ will be determined, making the follow-up of such cases more accurate and efficient.

\section{Acknowledgement}

No sources of funding were used in the preparation of this study.

\section{Statement of Ethics}

This study was performed in accordance with the standards of ethics outlined in the Declaration of Helsinki.

\section{Conflict of Interest Statement}

Nurdan Erol declares that they have no conflict of interests in relation to this review. The author has no conflicts of interest to declare.

\section{Funding Sources}

The author did not receive any funding.

\section{Author Contributions}

Nurdan Erol determined the subject of the review, prepared and wrote the article.

\section{References}

1 Lee MS, Chen $\mathrm{CH}$. Myocardial bridging: an up-to-date review. J Invasive Cardiol. 2015; 27(11):521-8.

2 Alegria JR, Herrmann J, Holmes DR Jr, Lerman A, Rihal CS. Myocardial bridging. Eur Heart J. 2005;26(12):1159-68.

3 Reyman HC. Disertatio de vasis cordis propriis. Bibl Anat. 1737;2:359-79.

4 Portsmann W, Iwig J. Die intramurale Koronarie im Angiogramm. Fortschr Geb Rontgenstr Nuklearmed. 1960;92:129-32.

5 Angelini P, Velasco JA, Flamm S. Coronary anomalies: incidence, pathophysiology, and clinical relevance. Circulation. 2002;105(20): 2449-54.

6 Corban MT, Hung OY, Eshtehardi P, RasoulArzrumly E, McDaniel M, Mekonnen G, et al. Myocardial bridging: contemporary understanding of pathophysiology with implications for diagnostic and therapeutic strategies. J Am Coll Cardiol. 2014;63(22):2346-55.
7 Ishikawa Y, Kawawa Y, Kohda E, Ishii T. (1) coronary events caused by myocardial bridge. Ann Vasc Dis. 2009;2(2):79-94.

8 Ishii T, Ishikawa Y, Akasaka Y. Myocardial bridge as a structure of "double-edged sword" for the coronary artery. Ann Vasc Dis. 2014; 7(2):99-108.

9 Mohlenkamp S, Hort W, Ge J, Erbel R. Update on myocardial bridging. Circulation. 2002;106:2616-22.

10 Ishikawa Y, Kawawa Y, Kohda E, Shimada K, Ishii T. Significance of the anatomical properties of a myocardial bridge in coronary heart disease. Circ J. 2011;75(7):1559-66.

11 Kim PJ, Hur G, Kim SY, Namgung J, Hong SW, Kim YH, et al. Frequency of myocardial bridges and dynamic compression of epicardial coronary arteries: a comparison between computed tomography and invasive coronary angiography. Circulation. 2009; 119(10): 1408-16.
12 Bourassa MG, Butnaru A, Lespérance J, Tardif JC. Symptomatic myocardial bridges: overview of ischemic mechanisms and current diagnostic and treatment strategies. J Am Coll Cardiol. 2003;41(3):351-9.

13 Yuan S. Myocardial bridging. Braz J Cardiovasc Surg. 2016;31(1):60-2.

14 Maeda K, Schnittger I, Murphy DJ, Tremmel JA, Boyd JH, Peng L, et al. Surgical unroofing of hemodynamically significant myocardial bridges in a pediatric population. $J$ Thorac Cardiovasc Surg. 2018;156(4):1618-26.

15 Yetman AT, McCrindle BW, MacDonald C, Freedom RM, Gow R. Myocardial bridging in children with hypertrophic cardiomyopathy: a risk factor for sudden death. N Engl J Med. 1998;339(17):1201-9. 
16 Mohiddin SA, Begley D, Shih J, Fananapazir L. Myocardial bridging does not predict sudden death in children with hypertrophic cardiomyopathy but is associated with more severe cardiac disease. J Am Coll Cardiol. 2000; 36(7):2270-8.

17 Lezzi F, Surace FC, Colaneri M, Capestro A, Pozzi M. A case of co-existence of muscle bridge and anomalous origin of coronary artery. Int J Surg Case Rep. 2019;57:67-70.

18 Daana M, Wexler I, Milgalter E, Rein AJ, Perles Z. Symptomatic myocardial bridging in a child without hypertrophic cardiomyopathy. Pediatrics. 2006;117(2):e333.

19 Kiess A, Vollroth M, Bakhtiary F, Seki H, Kostelka M, Djukic M, et al. Symptomatic myocardial bridging: a frequently occurring coronary variation can cause severe myocardial ischaemia in affected children with underlying cardiac conditions. Cardiol Young. 2018;28(6):826-31.

20 Gerlis LM, Magee AG, Sheppard MN. Congenital atresia of the orifice of the left coronary artery. Cardiol Young. 2002;12(1):5762.

21 Visscher DW, Miles BL, Waller BF. Tunneled ("bridged") left anterior descending coronary artery in a newborn without clinical or morphologic evidence of myocardial ischemia. Cathet Cardiovasc Diagn. 1983;9(5):493-6.

22 Mavi A, Sercelik A, Ayalp R, Karben Z, Batyraliev T, Gumusburun E. The angiographic aspects of myocardial bridges in Turkish patients who have undergone coronary angiography. Ann Acad Med Singap. 2008;37(1): 49-53.

23 Rogers IS, Tremmel JA, Schnittger I. Myocardial bridges: overview of diagnosis and management. Congenit Heart Dis. 2017;12(5): 619-23.

24 Ferreira AG Jr, Trotter SE, König B Jr, Décourt LV, Fox K, Olsen EG. Myocardial bridges: morphological and functional aspects. $\mathrm{Br}$ Heart J. 1991;66(5):364-7.

25 Cakmak YO, Cavdar S, Yalin A, Yener N, Ozdogmus O. Myocardial bridges of the coronary arteries in the human fetal heart. Anat Sci Int. 2010;85(3):140-4.

26 Çeauşu M, Ionescu RA, Malinescu B, Rusu MC, Hostiuc S, Dermengiu D. Sudden cardiac death due to triple myocardial bridging associated with atypical coronary topography. Rom J Morphol Embryol. 2013;54(3 Suppl): 833-7.

27 Angelini P, Trivellato M, Donis J, Leachman RD. Myocardial bridges: a review. Prog Cardiovasc Dis. 1983;26(1):75-88.

28 Konen E, Goitein O, Sternik L, Eshet Y, Shemesh J, Di Segni E. The prevalence and anatomical patterns of intramuscular coronary arteries: a coronary computed tomography angiographic study. J Am Coll Cardiol. 2007;49(5): 587-93.
29 Noble J, Bourassa MG, Petitclerc R, Dyrda I. Myocardial bridging and milking effect of the left anterior descending coronary artery: normal variant or obstruction? Am J Cardiol. 1976;37(7):993-9.

30 Schwarz ER, Gupta R, Haager PK, vom Dahl J, Klues HG, Minartz J, et al. Myocardial bridging in absence of coronary artery disease: proposal of a new classification based on clinical-angiographic data and long-term follow-up. Cardiology. 2009;112(1):13-21.

31 Ballesteros LE, Ramirez LM. Morphological expression of the left coronary artery: a direct anatomical study. Folia Morphol. 2008;67(2): $135-42$.

32 Lujinović A, Kulenović A, Kapur E, Gojak R. Morphological aspects of myocardial bridges. Bosn J Basic Med Sci. 2013;13(4):212-7.

33 Masuda T, Ishikawa Y, Akasaka Y, Itoh K, Kiguchi $\mathrm{H}$, Ishii $\mathrm{T}$. The effect of myocardial bridging of the coronary artery on vasoactive agents and atherosclerosis localization. J Pathol. 2001;193(3):408-14.

34 Mahani MG, Agarwal PP. Coronary artery anomalies on CT angiography. Radiology. 2011;40(6):18-25.

35 Uusitalo V, Saraste A, Pietilä M, Kajander S, Bax JJ, Knuuti J. The functional effects of intramural course of coronary arteries and its relation to coronary atherosclerosis. JACC Cardiovasc Imaging. 2015;8(6):697-704.

36 Cheng C, Tempel D, van Haperen R, van der Baan A, Grosveld F, Daemen MJ, et al. Atherosclerotic lesion size and vulnerability are determined by patterns of fluid shear stress. Circulation. 2006;113(23):2744-53.

37 Tarantini G, Migliore F, Cademartiri F, Fraccaro C, Iliceto S. Left anterior descending artery myocardial bridging. J Am Coll Cardiol. 2016;68:2887-99.

38 Ishimori T, Raizner AE, Chahine RA, Awdeh M, Luchi RJ. Myocardial bridges in man: clinical correlations and angiographic accentuation with nitroglycerin. Cathet Cardiovasc Diagn. 1977;3:59-65.

39 Juan CC, Hwang B, Lee PC, Meng CC. Diagnostic application of multidetector-row computed tomographic coronary angiography to assess coronary abnormalities in pediatric patients: comparison with invasive coronary angiography. Pediatr Neonatol. 2011;52(4):208.

40 Ge J, Jeremias A, Rupp A, Abels M, Baumgart $\mathrm{D}$, Liu F, et al. New signs characteristic of myocardial bridging demonstrated by intracoronary ultrasound and Doppler. Eur Heart J. 1999;20(23):1707-16.

41 Ge J, Erbel R, Rupprecht HJ, Koch L, Kearney $P$, Görge G, et al. Comparison of intravascular ultrasound and angiography in the assessment of myocardial bridging. Circulation. 1994;89(4):1725-32.

42 Escaned J, Cortés J, Flores A, Goicolea J, Alfonso F, Hernández R, et al. Importance of diastolic fractional flow reserve and dobutamine challenge in physiologic assessment of myocardial bridging. J Am Coll Cardiol. 2003; 42(2):226-33.
43 Gould KL, Johnson NP. Myocardial bridges: lessons in clinical coronary pathophysiology. JACC Cardiovasc Imaging. 2015;8(6):705.

44 Zeina AR, Odeh M, Blinder J, Rosenschein U, Barmeir E. Myocardial bridge: evaluation on MDCT. AJR Am J Roentgenol. 2007;188(4): 1069-73.

45 Yamada R, Tremmel JA, Tanaka S, Lin S, Kobayashi Y, Hollak MB, et al. Functional versus anatomic assessment of myocardial bridging by intravascular ultrasound: impact of arterial compression on proximal atherosclerotic plaque. J Am Heart Assoc. 2016;5(4):e001735.

46 Kobayashi Y, Tremmel JA, Kobayashi Y, Amsallem M, Tanaka S, Yamada R, et al. Exercise strain echocardiography in patients with a hemodynamically significant myocardial bridge assessed by physiological study. J Am Heart Assoc. 2015;4(11):e002496.

47 Kramer JR, Kitazume H, Proudfit WL, Sones FM. Clinical significance of isolated coronary bridges: benign and frequent condition involving the left anterior descending artery. Am Heart J. 1982;103(2):283-8.

48 De Winter RJ, Kok WE, Piek JJ. Coronary atherosclerosis within a myocardial bridge, not a benign condition. Heart. 1998;80(1):91-3.

49 Almeidaa AR, Pereiraa AR, Morgadoa GA, Loureiroa MJ, Ferreiraa F, Cruza I, et al. Three-vessel myocardial bridging: a possible cause of myocardial stunning. Rev Port Cardiol. 2019;38(3):225.e1-e5.

50 Cutler D, Wallace JM. Myocardial bridging in a young patient with sudden death. Clin Cardiol. 1997;20(6):581-3.

51 Pereira AB, Castro DSP, Menegotto ET, Amaral WM, Castro GSP. Myocardial bridging: therapeutic and clinical development. Arq Bras Cardiol. 2010;94(2):175-81.

52 Sharma J, Hellenbrand W, Kleinman C, Mosca R. Symptomatic myocardial bridges in children: a case report with review of literature. Cardiol Young. 2011;21(5):490-4.

53 Corrado D, Thiene G, Cocco P, Frescura C. Non-atherosclerotic coronary artery disease and sudden death in the young. Br Heart J. 1992;68(6):601-7.

54 Quaranta F, Guerra E, Sperandii F, De Santis F, Pigozzi F, Calò L, et al. Myocarditis in athlete and myocardial bridge: an innocent bystander? World J Cardiol. 2015 May 26;7(5): 293-8.

55 Hillman ND, Mavroudis C, Backer CL, Duffy CE. Supraarterial decompression myotomy for myocardial bridging in a child. Ann Thorac Surg. 1999;68(1):244-6.

56 van der Velde N, Huurman R, Yamasaki Y, Kardys I, Galema TW, Budde RPJ, et al. Frequency and significance of coronary artery disease and myocardial bridging in patients with hypertrophic cardiomyopathy. Am J Cardiol.2020;125:1404-12.

57 Reig J, Ruiz de Miguel C, Moragas A. Morphometric analysis of myocardial bridges in children with ventricular hypertrophy. Pediatr Cardiol. 1990;11(4):186-90. 
58 Hostiuc S, Rusu MC, Hostiuc M, Negoi RI, Negoi I. Cardiovascular consequences of myocardial bridging: a metaanalysis and meta-regression. Sci Rep. 2017 Nov 7;7(1):14644.

59 Ishikawa Y, Akasaka Y, Akishima-Fukasawa Y, Iuchi A, Suzuki K, Uno M, et al. Histopathologic profiles of coronary atherosclerosis by myocardial bridge underlying myocardial infarction. Atherosclerosis. 2013;226(1):11823.

60 Saito Y, Kitahara H, Shoji T, Tokimasa S, Nakayama T, Sugimoto K, et al. Relation between severity of myocardial bridge and vasospasm. Int J Cardiol. 2017;248:34-8.

61 Pittaluga J, de Marchena E, Posada JD, Romanelli R, Morales A. Left anterior descending coronary artery bridge: a cause of early death after cardiac transplantation. Chest. 1997;111:511-3.

62 Migliore F, Maffei E, Perazzolo Marra M, Bilato C, Napodano M, Corbetti F, et al. LAD coronary artery myocardial bridging and apical ballooning syndrome. JACC Cardiovasc Imaging. 2013;6(1):32-41.

63 Kato K, Kitahara H, Saito Y, Fujimoto Y, Sakai Y, Ishibashi I, et al. Impact of myocardial bridging on in-hospital outcome in patients with takotsubo syndrome. J Cardiol. 2017; 70(6):615-9.

64 Schwarz ER, Klues HG, vom Dahl J, Klein I, Krebs W, Hanrath P. Functional, angiographic and intracoronary doppler flow characteristics in symptomatic patients with myocardial bridging: effect of short-term intravenous beta-blocker medication. J Am Coll Cardiol. 1996;27(7):1637-45.
65 Kursakliglu H, Barcin C, Iyisoy A, Kose S, Amasyali B, Isik E. Angiographic restenosis after myocardial bridge stenting a comparative study with direct stenting of de-novo atherosclerotic lesions. Jpn Heart J. 2004;45:5819.

66 HaagerPK, Schwarz ER, Dahl JV, Klues HG, Reffelmann T, Hanrath P. Long term angiographic and clinical follow up in patients with stent implantation for symptomatic myocardial bridging. Heart. 2000;84:403-8.

67 Pourhoseini S, Bakhtiari M, Babaee A, Ostovan MA, Eftekhar-Vaghefi SH, Ostovan N, et al. Increased risk of coronary perforation during percutaneous intervention of myocardial bridge: what histopathology says. J Cardiovasc Thorac Res. 2017;9(2):108-12.

68 Grondin P, Bourassa MG, Noble J, Petitclerc R, Dydra I. Successful course after supraarterial myotomy for myocardial bridging and milking effect of the left anterior descending artery. Ann Thorac Surg. 1977;24(5):422-9.

69 Boyd JH, Pargaonkar VS, Scoville DH, Rogers IS, Kimura T, Tanaka S, et al. Surgical unroofing of hemodynamically significant left anterior descending myocardial bridges. Ann Thorac Surg. 2017;103(5):1443-50.

70 Kunkala MR, Schaff HV, Burkhart H, Sandhu GS, Spoon DB, Ommen SR, et al. Outcome of repair of myocardial bridging at the time of septal myectomy. Ann Thorac Surg. 2014; 97(1):118-23.
71 Qing-yu WU, Zhong-hua XU. Surgical treatment of myocardial bridging: report of 31 cases. Chin Med J. 2007;120(19):1689-93.

72 Huang XH, Wang SY, Xu JP, Song YH, Sun HS, Tang Y, et al. Surgical outcome and clinical follow-up in patients with symptomatic myocardial bridging. Chin Med J. 2007; 120(18):1563-6.

73 Downar J, Williams WG, McDonald C, Wigle ED, McCrindle BW. Outcomes after "unroofing" of a myocardial bridge of the left anterior descending coronary artery in children with hypertrophic cardiomyopathy. Pediatr Cardiol. 2004;25(4):390-3.

74 Kikuchi S, Okada K, Hibi K, Maejima N, Matsuzawa Y, Konishi M, et al. Myocardial infarction caused by accelerated plaque formation related to myocardial bridge in a young man. Can J Cardiol. 2018 Dec;34(12):1687. e13-15.

75 Mery CM, Lopez KN, Molossi S, Sexson-Tejtel SK, Krishnamurthy R, McKenzie ED, et al. Decision analysis to define the optimal management of athletes with anomalous aortic origin of a coronary artery. J Thorac Cardiovasc Surg. 2016;152:1366-75.

76 Kim SS, Jeong MH, Kim HK, Kim MC, Cho $\mathrm{KH}$, Lee MG, et al. Long-term clinical course of patients with isolated myocardial bridge. Circ J. 2010;74(3):538-43.

77 Dimitriu-Leen AC, van Rosendael AR, Smit JM, van Elst T, van Geloven N, Maaniitty T, et al. Long-term prognosis of patients with intramural course of coronary arteries assessed with CT angiography. JACC Cardiovasc Imaging. 2017;10:1451-8 